TITLE:

\title{
Manufacture of a weakly denatured collagen fiber scaffold with excellent biocompatibility and space maintenance ability.
}

\section{AUTHOR(S):}

Nakada, A; Shigeno, K; Sato, T; Kobayashi, T; Wakatsuki, M; Uji, M; Nakamura, T

\section{CITATION:}

Nakada, A ... [et al]. Manufacture of a weakly denatured collagen fiber scaffold with excellent biocompatibility and space maintenance ability.. Biomedical materials 2013, 8(4): 45010.

\section{ISSUE DATE:}

2013-06-27

URL:

http://hdl.handle.net/2433/177968

\section{RIGHT:}

(C) 2013 IOP Publishing; 許諾条件により本文は2014-06-28に公開; この 論文は出版社版でありません。引用の際には出版社版をご確認ご利用 ください。; This is not the published version. Please cite only the published version. 


\section{Manufacture of a weakly denatured collagen fiber scaffold with excellent biocompatibility and space maintenance} ability

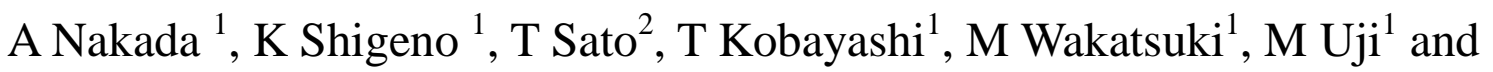
T Nakamura ${ }^{1 *}$

${ }^{1}$ Department of Bioartificial Organs, Institute for Frontier Medical Sciences, Kyoto University

${ }^{2}$ Department of Thoracic Surgery, Kyoto University

Running head: Manufacture of a weakly denatured collagen

"Corresponding author: Department of Bioartificial Organs, Institute for Frontier Medical Sciences, Kyoto University, 53 Kawahara-cho, Shogoin, Sakyo-ku, Kyoto 606-8507, Japan

Tel: 81-75-751-4149; fax: 81-75-751-4844; email: nakamura@ frontier.kyoto-u.ac.jp, nakada@frontier.kyoto-u.ac.jp 


\begin{abstract}
Although collagen scaffolds have been used for regenerative medicine, they have insufficient mechanical strength. We made a weakly denatured collagen fiber scaffold from a collagen fiber suspension (physiological $\mathrm{pH}$ 7.4) through a process of freeze-drying and denaturation with heat under low pressure $\left(1 \times 10^{-1} \mathrm{~Pa}\right)$. Heat treatment formed cross-links between the collagen fibers, providing the scaffold with sufficient mechanical strength to maintain the space for tissue regeneration in vivo. The scaffold was embedded under the back skin of a rat, and biocompatibility and space maintenance ability was examined after 2 weeks. These were evaluated by using the ratio of foreign body giant cells and thickness of the residual scaffold. A weakly denatured collagen fiber scaffold with moderate biocompatibility and space maintenance ability was made by freezing at $-10^{\circ} \mathrm{C}$, followed by denaturation at $140^{\circ} \mathrm{C}$ for $6 \mathrm{hr}$. In addition, the direction of the collagen fibers in the scaffold was adjusted by cooling the suspension only from the bottom of the container. This process increased the ratio of cells that infiltrated into the scaffold. A weakly denatured collagen fiber scaffold thus made can be used for tissue regeneration or delivery of cells or proteins to a target site.
\end{abstract}

Keywords: collagen; scaffold; biocompatible materials; regeneration 


\section{Introduction}

Various materials have been developed as "scaffolds" for regenerative medicine. A typical scaffold of synthetic polymers may contain poly-glycolic acid (PGA), poly-L-lactic acid (PLLA), and poly-lactic-co-glycolic acid (PLGA), and scaffolds of natural polymers contain collagen and gelatin. These scaffolds have been used in clinical practice and yield adequate results [1-7]. However, PGA, PLLA, and PLGA scaffolds may cause needless adhesion or toxicity because they may reduce the $\mathrm{pH}$ of the surrounding tissue [8-10]. We found that a collagen fiber scaffold manufactured at physiological $\mathrm{pH}$ was biocompatible and yielded no adhesion. However, it dissolved before tissue regeneration was complete. Various modifications may therefore be needed [11-14]. Glutaraldehyde (GA) and N-(3-dimethylaminopropyl)-N'-ethylcarbodiimide hydrochloride (EDC) are well known chemical cross-linkers. Although defects may make chemical cross-linkers cytotoxic [15], EDC has relatively low cytotoxicity and is useful as a cross-linker $[12,14,16]$. UV is used for physical cross-linking; it does not involve toxic chemicals [15], but cannot provide sufficient stiffness in a collagen scaffold [16]. We examined thermal processing as a simple physical cross-linking method. We made a collagen fiber scaffold by freeze-drying a collagen fiber suspension with a physiological $\mathrm{pH}$ of 7.4. This was followed by heating under negative pressure. Heating formed cross-links between the collagen fibers, providing sufficient strength to maintain a space for tissue regeneration against the pressure of surrounding tissue or collagenase [17]. In this study, mechanical strength is defined as the ability to maintain space for tissue regeneration, rather than mere physical strength; this characteristic is important for regenerative medicine. The scaffold was embedded under the back skin of a rat to determine if it had sufficient biocompatibility and space maintenance ability to be used as a scaffold for regenerative medicine.

Collagen forms a molecular structure under acidic conditions, but forms fibers under 
neutral conditions, and the modes shift reversibly. Furthermore, it can be denatured by exposure to heat (denatured collagen, which contains $0 \%$ super-helix structure, is called gelatin). The temperature by which half of the collagen molecules have lost their super-helix structure is called the "denaturation temperature". The denaturation temperature in the dehydrated state is around $112^{\circ} \mathrm{C}[18]$. The collagen fiber scaffold evaluated in this study was freeze-dried and heated under negative pressure. Thermal processing above the denaturation temperature introduced various chemical changes including cross-linking $[19,20]$ and provided mechanical strength [21, 22]. However, as denaturation and mechanical strength of the scaffold increases, the host's foreign-body reaction also increases. As a result, the scaffold is no longer suitable for use in the body. Therefore, it is important to create a scaffold with moderate mechanical strength to minimize foreign-body reaction. In addition, collagen fiber becomes a barrier with increased mechanical strength, and the number of cells invading the scaffold decreases (figure 1a). Therefore, our scaffold was designed to promote cell infiltration by orienting the collagen fibers (figure 1b). As an icy crystal is formed perpendicular to a cooling surface, orientation was achieved by cooling a collagen fiber suspension only from the bottom of the container.

To determine the optimal denaturing conditions to create an ideal scaffold with excellent space maintenance ability and biocompatibility, various types of denatured collagen fiber scaffolds with orientation were embedded under the back skin of rats. The optimal observation period was determined to be 2 weeks because it was important to maintain the scaffold at least during the acute or subacute phase of trauma for tissue regeneration. The in vivo behavior of these implants was evaluated by determining their space maintenance and biocompatibility scores.

\section{Materials and Methods}

\subsection{Manufacturing of denatured collagen fiber scaffold}

The collagen used in this study was atelocollagen extracted from young porcine skin by 
enzymatic treatment with pepsin (NMP collagen PS, provided by Nippon Meatpackers, Ibaraki, Japan) and consisting of type I (70-80\%) and type III collagen. From this, the collagen mass (pH 7) was made according to the protocol provided with the product. Briefly, $30 \mathrm{~g}$ NMP collagen PS was added to $5 \mathrm{~L}$ distilled water $(0.6 \% \mathrm{w} / \mathrm{v})$ and the mixture was stirred in the refrigerator overnight to make a collagen solution. After adjusting the $\mathrm{pH}$ to 7 with $1 \mathrm{~N} \mathrm{NaOH}$, the solution was centrifuged to collect the deposit, which was freeze-dried to yield a collagen mass. Next, the mass was crushed with a grater to yield particles of approximately $2 \times 2 \times 2$ $\mathrm{mm}^{3}$ and $6 \mathrm{~g}$ were added to $200 \mathrm{~mL}$ sterilized Milli-Q water. The mixture was stirred in a Hybrid Mixer (HM-500, Keyence, Osaka, Japan) for $2 \mathrm{~min}$, then cooled at $4^{\circ} \mathrm{C}$ for more than 30 min. This process was repeated 5 times to yield a $3 \% \mathrm{w} / \mathrm{v}$ uniform collagen fiber suspension. The suspension was stored at $4^{\circ} \mathrm{C}$ for $12 \mathrm{hr}$ to create a uniform suspension. The $\mathrm{pH}$ of the collagen fiber suspension was adjusted to 7.4 with $1 \mathrm{~N} \mathrm{NaOH}$ and stirred in an Ace Homogenizer (HM-500, Nissei, Tokyo, Japan) at $5000 \mathrm{rpm}$ for $30 \mathrm{~min}$. This allowed the internal structure of the collagen fiber scaffold to become uniform. The suspension, which became paste-like, was poured into a container (figure 2) and frozen at $-10^{\circ} \mathrm{C}$. Since an icy crystal forms perpendicular to a cooling surface, orientation can be achieved by cooling the collagen fiber suspension only from the bottom of the container (the fibers will orient perpendicular to the bottom). After $12 \mathrm{hr}$, the frozen suspension was freeze-dried for 3 days and was heat-denatured under low pressure (1 $\times 10^{-1} \mathrm{~Pa}$ ) to form a denatured collagen fiber scaffold. Manufacturing conditions are shown in table 1 . Since the pore size of the collagen fiber scaffold within about $5 \mathrm{~mm}$ from the cooling surface is too small and the ratio of cell infiltration is small, only that portion of the scaffold $>5$ $\mathrm{mm}$ from the bottom was used. To investigate the internal structure of the scaffold, scanning electron microscopy was performed prior to placement in the experimental animals. After being cut into $1 \mathrm{~cm} \times 1 \mathrm{~cm} \times 5 \mathrm{~mm}$ sections (figure $3 \mathrm{a}$ ), the collagen fiber scaffold was sterilized with ethylene oxide gas prior to implantation. 


\subsection{Animal and surgical procedures}

Male Wistar rats (500 g, Shimizu Laboratory Supply, Kyoto, Japan) were used for this study. Under anesthesia induced by intraperitoneal injection of sodium pentobarbital ( $3 \mathrm{mg} / 100 \mathrm{~g}$ body weight), each rat was placed in a prone position. Next, 6 incisions, measuring about $15 \mathrm{~mm}$ in length, were made on the back skin of each rat, and pockets to embed collagen fiber scaffolds were made using Pean forceps. Then the collagen fiber scaffolds were inserted into the pockets. Three pockets on 3 individual rats were used for each scaffold. That is, three scaffolds were used for each manufacturing condition. After embedding the scaffolds, the skin was closed with 3-0 nylon suture (figure 3b). Tissue evaluation was performed 2 weeks after the procedure.

In order to evaluate the effect of collagen fiber orientation in the scaffold, 3 samples with orientation, and 3 samples without orientation were used. In the preliminary study, we found that scaffolds processed at $140^{\circ} \mathrm{C}-24 \mathrm{hr}$ had poor biocompatibility; therefore, we used these conditions in order to evaluate only the effect of collagen fiber orientation. Tissue evaluation was performed 1 week after the operation, since it is ideal for cellular infiltration of the scaffold to occur in the early stage of implantation.

All surgical experiments were performed according to the Principle of Laboratory Animal Care advocated by the Animal Research Committee of Kyoto University (2007).

\subsection{Evaluation}

Histology. Two weeks after scaffold implantation, the rats were sacrificed by an overdose injection (intraperitoneal) of sodium pentobarbital. The back skin of each rat was stripped and fixed with $4 \%$ paraformaldehyde for more than $72 \mathrm{hr}$ at room temperature. All samples were extracted with skin, then dehydrated through ascending alcohol concentrations, embedded in paraffin, serially sectioned $(4 \mu \mathrm{m})$ in the perpendicular plane, dewaxed, and stained with hematoxylin-eosin (H-E). Thereafter, the sections were examined by light microscopy (BIOREVO BZ-9000, Keyence, Osaka, Japan). 
Space maintenance ability. Although the scaffold should ideally disappear from the body after a certain period, it must remain in vivo at least until tissue regeneration is complete. In this study, we observed a tendency for the thickness of the specimen on the prepared slide to increase as denaturation advanced; thus, the space maintenance ability was scored by using thickness as an index.

(Thickness score: TS)

(1) The average thickness of 3 samples $=0 \mathrm{~mm} . \rightarrow \mathrm{TS}=1$

(2) The average thickness of 3 samples $>0 \mathrm{~mm} . \rightarrow \mathrm{TS}=2+($ Average thickness/1000)

(Since no space is identified when TS is below 2, a TS-2 is considered the lowest level required for the scaffold.)

Tissue shrinks during the process of preparing a slide. In other words, the thickness of the specimen on the prepared slide becomes thinner than $5 \mathrm{~mm}$ even if the prepared slide containing a 5-mm scaffold is made just after being embedded under the skin. Therefore, the thickness of the collagen fiber scaffold 2 weeks after the operation is actually thicker than that on the prepared slide. In this study, space maintenance ability was evaluated based on the thickness of the specimen on a prepared slide.

Biocompatibility. Once the living body recognizes a foreign body, macrophages are dispatched to eliminate the object. However, the macrophages fuse and become a foreign body giant cell in response to a large foreign body. In other words, the presence of a foreign body giant cell indicates the body has recognized a large foreign body. In this study, the scaffold in which many foreign body giant cells were identified caused a strong inflammatory reaction and could never be used to construct tissue, even if it remained in place 2 weeks after surgery. Therefore, "the degree of foreign body" of the scaffold is evaluated by the following score.

(Biocompatibility score: BS)

(1) BS-1: Foreign body giant cells are identified around the embedded collagen fiber scaffold.

(2) BS-2; Foreign body giant cells are identified around only a portion of the embedded 
collagen fiber scaffold.

(3) BS-3: Few foreign body giant cells are identified around the embedded collagen fiber scaffold. (Since a foreign-body reaction appeared below BS-3, this is considered the lowest level of biocompatibility.)

(4) BS-4: No foreign body giant cells are identified around the embedded collagen fiber scaffold.

\section{Results}

Macroscopic and electron microscopic images of the collagen fiber scaffolds were collected.

There was no orientation of collagen fibers unless the suspension was cooled from one direction (figure 1c, e). Cooling from the bottom of the container yielded collagen fibers arranged perpendicular to the cooling surface, and the pore sizes of this scaffold measured 100 to $300 \mu \mathrm{m}$ (figure 1d, f). The infiltration of cells perfusing the scaffold slowed when the collagen fiber was not oriented properly (figure $1 \mathrm{~g}$ ). This result was the same for all samples processed at $140^{\circ} \mathrm{C}-24 \mathrm{hr}$ without collagen fiber orientation. On the other hand, infiltration improved when the collagen fiber in the scaffold was oriented in a single direction (figure 1h). This result was the same for all samples processed at $140^{\circ} \mathrm{C}-24 \mathrm{hr}$ with collagen fiber orientation.

We evaluated the relationship between manufacturing conditions and the properties of the created collagen fiber scaffold (table 2). Denaturation of the collagen at $140^{\circ} \mathrm{C}$ for $6 \mathrm{hr}$ produced a collagen fiber scaffold with TS greater than 2 and BS-3 at 2 weeks after implantation. However, denaturation at $140^{\circ} \mathrm{C}$ for more than $12 \mathrm{hr}$ yielded no biocompatibility (BS-1). "Impossible to evaluate" indicates that it was impossible to evaluate the collagen fiber scaffold because it had disappeared 2 weeks after it was embedded. This indicated insufficient denaturation. The comment noted in the table as "Impossible to evaluate" was therefore considered to indicate BS-3. However, as for $140^{\circ} \mathrm{C}-0 \mathrm{hr}$, it was evaluated as BS-4. 


\section{Discussion}

A collagen microfibril contains 5 collagen molecules [23-26]; collagen fibrils are formed by aggregation of these microfibrils. Collagen fiber is an assembly of these fibrils. The main epitope of a collagen fiber is in the non-spiral structural telopeptides at both ends of the collagen molecule, and the remainder of the molecule differs little between animal classes.

The collagen used in this experiment is atelocollagen, which is produced by elimination of the antigenic telopeptides by pepsin. The biocompatibility of atelocollagen without denaturation is very high because BS is 4 at 1 week after embedding. However, there is poor infiltration of cells because spaces for tissue regeneration are not maintained (figure 4a). Moreover, it was nearly dissolved 2 weeks after embedding. On the other hand, although the mechanical strength increased and sufficient space was maintained even 2 weeks after the operation, antigenicity of the collagen fiber scaffold increased and tissue construction could not be identified when thermal processing was performed at $140^{\circ} \mathrm{C}$ for $24 \mathrm{hr}$. Therefore, the collagen fiber scaffold was recognized as a foreign body with low biocompatibility (figure $4 b$ ). This resulted in a foreign body giant cell with multiple nuclei surrounding the scaffold (figure 4c). Thus, mechanical strength was inversely proportional to biocompatibility. It is thought that optimal "weak denaturation" occurs at a processing temperature of $140^{\circ} \mathrm{C}$ between 0 and $24 \mathrm{hr}$; we concluded the optimal time was $6 \mathrm{hr}$ (figure 5a). Figure 5a is drawn based on the results of 3 samples at $140^{\circ} \mathrm{C}-0,6,9,12$, and $24 \mathrm{hr}$ (shown in table 2). Figure 5a illustrates that although biocompatibility is good, the space maintenance ability is inferior when processing time is shorter than $6 \mathrm{hr}$. On the other hand, the space maintenance ability is superior, but biocompatibility declines when the processing time is longer than $6 \mathrm{hr}$. Since collagen denaturation progresses over time [27], the BS curve shown in figure 5a declined even if the BS score was the same. The graph accurately reflected the properties of the collagen fiber scaffold indicated in table 2.

Cells infiltrate the collagen fiber scaffold along collagen fibers; thus, the infiltration rate 
improved when the scaffold with collagen fiber orientation was used. This is likely because continuous holes are made in the scaffold. This improvement is also likely to ease neovascularity. It is important to ensure blood flow around the region of tissue regeneration to maintain the infiltrated cells. Moreover, when a collagen fiber scaffold containing disseminated cells is implanted, neovascularity in the early phase is also required to maintain the viability of the disseminated cells. Therefore, orientation of the collagen fibers in a scaffold should improve tissue regeneration. Particularly in the case of hard biomaterials used for bone regeneration, continuous holes greatly improve cell infiltration [28, 29]. Bone tissue engineering reports have suggested the utility of a complex of collagen and glycosaminoglycan (GAG). Tierney et al. reported that a scaffold with suitable mechanical and biological properties was produced by treatment at $150^{\circ} \mathrm{C}-48 \mathrm{hr}[30]$ and Haugh et al. reported scaffolds treated at $150^{\circ} \mathrm{C}-120 \mathrm{hr}$ or $180^{\circ} \mathrm{C}-24 \mathrm{hr}[31]$. The results of both thermal processing methods are far stronger than our results. However, we also found that strong thermal processing at $140^{\circ} \mathrm{C}-24 \mathrm{hr}$ is suitable for producing a collagen scaffold with the desired mechanical properties. Drexler et al. used the dehydrothermal crosslinking method and reported that thermal processing at $140^{\circ} \mathrm{C}-24 \mathrm{hr}$ improved mechanical properties and biostability [17]. However, these reports utilized collagen molecules under acidic conditions. Since the properties of collagen molecules are different from those of the collagen fibers used in this study, it is difficult to compare the thermal processing conditions mentioned by Drexler et al. with the thermal processing condition used in this study $\left(140^{\circ} \mathrm{C}-6 \mathrm{hr}\right)$.

Pore size can be controlled by freezing temperature; pore size becomes smaller as the freezing temperature decreases. Though we made a weakly denatured collagen fiber scaffold by freezing at $-80^{\circ} \mathrm{C}[32,33]$, the pore sizes were small and few cells infiltrated the scaffold. Since the pore sizes of the present scaffold measured from 100 to $300 \mu \mathrm{m}$, freezing at $-10^{\circ} \mathrm{C}$ is considered suitable for cell infiltration.

Although the results of this study demonstrated that the most suitable denaturation 
condition is $140^{\circ} \mathrm{C}-6 \mathrm{hr}$, it is possible to apply $140^{\circ} \mathrm{C}-5 \mathrm{hr}$ for tissue regeneration, as shown in figure 5a. Under these conditions, biocompatibility is slightly improved, while space maintenance ability decreases.

When the scaffolds manufactured under $140^{\circ} \mathrm{C}-6 \mathrm{hr}$ and $140^{\circ} \mathrm{C}-9 \mathrm{hr}$ conditions were evaluated at 2 and 3 weeks after the operation, the longer-treated scaffold had a greater thickness, while the more briefly heated scaffold demonstrated better biocompatibility, a difference that increased by 3 weeks. Inflammatory cell infiltration was identified in scaffolds processed at $140^{\circ} \mathrm{C}-9 \mathrm{hr}$ as soon as 3 weeks after operation (figure $5 \mathrm{~b}$ ). This is consistent with the trend demonstrated in figure 5a.

The results of denaturation at $100^{\circ} \mathrm{C}$ and $120^{\circ} \mathrm{C}$ are shown in figure 6 . The TS at $100^{\circ} \mathrm{C}-6 \mathrm{hr}$ and $24 \mathrm{hr}$ are 1 and the BS at $100^{\circ} \mathrm{C}-6 \mathrm{hr}$ and $24 \mathrm{hr}$ are 3 . Since $100^{\circ} \mathrm{C}$ is below the denaturation temperature, the line indicating BS is considered almost parallel to the horizontal axis. Denaturation at $120^{\circ} \mathrm{C}$ for 18 to less than $24 \mathrm{hr}$ (time $\mathrm{x}$ ) also yielded a scaffold with space maintenance ability and biocompatibility. Therefore, other manufacturing conditions may produce an adequate scaffold. In a previous study, we noted that although the scaffold processed at $120^{\circ} \mathrm{C}-24 \mathrm{hr}$ was always present even 2 weeks after the operation, the scaffold processed at $120^{\circ} \mathrm{C}-23 \mathrm{hr}$ was not present in about $50 \%$ of cases $(n=6)$. We believe the scaffold should remain in place for at least 2 weeks in order to effectively function as a scaffold, so a TS at $120^{\circ} \mathrm{C}-23 \mathrm{hr}$ is considered to be "1". Therefore, the time, $\mathrm{x}$, should be between $23 \mathrm{hr}$ and $24 \mathrm{hr}$.

A similar experiment is underway using a $6 \%$ weakly denatured collagen fiber scaffold. Though the BS was 3, like that of the 3\% weakly denatured collagen fiber scaffold 2 weeks after embedding, cells infiltration was poor. This was because the high viscosity of the $6 \%$ collagen fiber suspension made it difficult to orient the collagen fibers. In addition, partition of the denatured collagen fiber is thick. A 6\% collagen scaffold with orientation can be made occasionally. In such cases, cells infiltrate even to the center of the scaffold along the collagen fiber 2 weeks after the operation. However, few cells infiltration can be identified in scaffolds 
without orientation. Therefore, orientation becomes more important when the viscosity is high.

Future experiments will investigate the optimal scaffold strength for specific organs, while reducing the density of the collagen fiber suspension to $6 \%$ or less. The shape of our scaffold remains smooth if it is pressed on a plate under conditions at which water is being fully absorbed. Although almost all collagen scaffold materials are made from collagen molecules under acidic conditions, this property is not apparent in acidic collagen scaffolds, including the ones examined in our previous study. The recovery of the scaffold's smooth surface may contribute to space maintenance for tissue regeneration in vivo. Moreover, our scaffold is easily infiltrated with cells if it is pressed several times in cell suspension. This property is useful in the field of cell transplantation [34]. Recently, research efforts to develop a tissue with a three-dimensional structure in vitro have been rapidly advancing, and the collagen scaffold developed in this study will be a useful material in various fields.

\section{Conclusions}

We concluded that collagen denaturation at $140^{\circ} \mathrm{C}$ for $6 \mathrm{hr}$ produced a scaffold for tissue regeneration with superior space maintenance ability and biocompatibility. Moreover, we suggest that orientation of the collagen fiber in the scaffold facilitates cell infiltration. The concentration of collagen fiber suspension was $3 \% \mathrm{w} / \mathrm{v}$ in this study, but it is possible to control the mechanical strength or the period the scaffold remains in vivo by changing the concentration. However, further studies will be necessary to elucidate these conditions. By repeating this process, we think the most suitable scaffold can be produced for any given purpose.

\section{Acknowledgments}

We thank T. Miura (Department of Anatomy and Developmental Biology, Kyoto University Graduate School of Medicine, Japan) for investigating cell affinity to the scaffold and T. Ueda (a member of the T. Kawai laboratory, Department of Robotics Osaka Institute of Technology, 
Japan) for valuable assistance in evaluating sample quality. 


\section{References}

1. Akita S, Akino K, Hirano A, Ohtsuru A, Yamashita S. 2010 Noncultured autologous adipose-derived stem cells therapy for chronic radiation injury. Stem Cells Int. $\mathbf{2 0 1 0}$ 532704.

2. Bushnell BD, McWilliams AD, Whitener GB, Messer TM. 2008 Early clinical experience with collagen nerve tubes in digital nerve repair. J Hand Surg Am. 33 1081-1087.

3. Kato Y, Matsumoto I, Tomita S, Watanabe G. 2009 A novel technique to prevent intra-operative pneumothorax in awake coronary artery bypass grafting: biomaterial neo-pleura. Eur J Cardiothorac Surg. 35 37-41.

4. Ueda K, Tanaka T, Li TS, Tanaka N, Hamano K. 2010 Sutureless pneumostasis using bioabsorbable mesh and glue during major lung resection for cancer: who are the best candidates? J Thorac Cardiovasc Surg. 139 600-605.

5. Waitayawinyu T, Parisi DM, Miller B, Luria S, Morton HJ, Chin SH, Trumble TE. 2007 A comparison of polyglycolic acid versus type 1 collagen bioabsorbable nerve conduits in a rat model: an alternative to autografting. J Hand Surg Am. 32 1521-1529.

6. Inada Y, Morimoto S, Takakura Y, Nakamura T. 2004 Regeneration of peripheral nerve gaps with a polyglycolic acid-collagen tube. Neurosurgery. 55 640-646; discussion 646-648.

7. Seo K, Inada Y, Terumitsu M, Nakamura T, Horiuchi K, Inada I, Someya G. 2008 One year outcome of damaged lingual nerve repair using a PGA-collagen tube: a case report. J Oral Maxillofac Surg. 66 1481-1484.

8. Ignatius AA, Claes LE. 1996 In vitro biocompatibility of bioresorbable polymers: poly(L, DL-lactide) and poly(L-lactide-co-glycolide). Biomaterials. 17 831-839. 
9. Suganuma J, Alexander H. 1993 Biological response of intramedullary bone to poly-L-lactic acid Journal of Applied Biomaterials. 4 13-27.

10. Nakamura T, Suzuki K, Mochizuki T, Ohde Y, Kobayashi H, Toyoda F. 2010 An evaluation of the surgical morbidity of polyglycolic acid felt in pulmonary resections. Surg Today. 40 734-737.

11. Lee H, Yeo M, Ahn S, Kang DO, Jang CH, Park GM, Kim GH. 2011 Designed hybrid scaffolds consisting of polycaprolactone microstrands and electrospun collagen-nanofibers for bone tissue regeneration. J Biomed Mater Res B Appl Biomater. 97 263-270.

12. Powell HM, Boyce ST. 2009 Engineered human skin fabricated using electrospun collagen-PCL blends: morphogenesis and mechanical properties. Tissue Eng Part A. 15 2177-2187.

13. Lu Q, Zhang S, Hu K, Feng Q, Cao C, Cui F. 2007 Cytocompatibility and blood compatibility of multifunctional fibroin/collagen/heparin scaffolds. Biomaterials. $\mathbf{2 8}$ 2306-2313.

14. Ma L, Gao C, Mao Z, Zhou J, Shen J. 2004 Enhanced biological stability of collagen porous scaffolds by using amino acids as novel cross-linking bridges. Biomaterials. 25 2997-3004.

15. Khor E. 1997 Methods for the treatment of collagenous tissues for bioprostheses. Biomaterials. 18 95-105.

16. Torres-Giner S, Gimeno-Alcaniz JV, Ocio MJ, Lagaron JM. 2009 Comparative performance of electrospun collagen nanofibers cross-linked by means of different methods. ACS Appl Mater Interfaces. 1 218-223.

17. Drexler JW, Powell HM. 2010 DHT Crosslinking of Electrospun Collagen. Tissue Eng 
Part C Methods. 17 9-17.

18. Sobol E, Sviridov A, Omel'chenko A, Bagratashvili V, Kitai M, Harding SE, Jones N, Jumel K, Mertig M, Pompe W, Ovchinnikov Y, Shekhter A, Svistushkin V. 2000 Laser reshaping of cartilage. Biotechnol Genet Eng Rev. 17 553-578.

19. Gorham SD, Light ND, Diamond AM, Willins MJ, Bailey AJ, Wess TJ, Leslie NJ. 1992 Effect of chemical modifications on the susceptibility of collagen to proteolysis. II. Dehydrothermal crosslinking. Int J Biol Macromol. 14 129-138.

20. Weadock K, Olson RM, Silver FH. 1983 Evaluation of collagen crosslinking techniques. Biomater Med Devices Artif Organs. 11 293-318.

21. Koide M, Osaki K, Konishi J, Oyamada K, Katakura T, Takahashi A, Yoshizato K. 1993 A new type of biomaterial for artificial skin: dehydrothermally cross-linked composites of fibrillar and denatured collagens. J Biomed Mater Res. 27 79-87.

22. Wang MC, Pins GD, Silver FH. 1994 Collagen fibres with improved strength for the repair of soft tissue injuries. Biomaterials. 15 507-512.

23. Gautieri A, Vesentini S, Redaelli A, Buehler MJ. 2011 Hierarchical structure and nanomechanics of collagen microfibrils from the atomistic scale up. Nano Lett. 11 $757-766$.

24. Moeller HD, Bosch U, Decker B. 1995 Collagen fibril diameter distribution in patellar tendon autografts after posterior cruciate ligament reconstruction in sheep: changes over time. J Anat. 187 ( Pt 1) 161-167.

25. Orgel JP, Irving TC, Miller A, Wess TJ. 2006 Microfibrillar structure of type I collagen in situ. Proc Natl Acad Sci U S A. 103 9001-9005.

26. King G, Brown EM, Chen JM. 1996 Computer model of a bovine type I collagen microfibril. Protein Eng. 9 43-49. 
27. Ueda H, Nakamura T, Yamamoto M, Nagata N, Fukuda S, Tabata Y, Shimizu Y. 2003 Repairing of rabbit skull defect by dehydrothermally crosslinked collagen sponges incorporating transforming growth factor beta1. J Control Release. 88 55-64.

28. Hamada H, Ohshima H, Ito A, Higuchi WI, Otsuka M. 2010 Effect of geometrical structure on the biodegradation of a three-dimensionally perforated porous apatite/collagen composite bone cell scaffold. Biol Pharm Bull. 33 1228-1232.

29. Lee KW, Wang S, Dadsetan M, Yaszemski MJ, Lu L. 2010 Enhanced cell ingrowth and proliferation through three-dimensional nanocomposite scaffolds with controlled pore structures. Biomacromolecules. 11 682-689.

30. Tierney CM, Haugh MG, Liedl J, Mulcahy F, Hayes B, O'Brien FJ. 2009 The effects of collagen concentration and crosslink density on the biological, structural and mechanical properties of collagen-GAG scaffolds for bone tissue engineering. J Mech Behav Biomed Mater. 2 202-209.

31. Haugh MG, Jaasma MJ, O'Brien FJ. 2009 The effect of dehydrothermal treatment on the mechanical and structural properties of collagen-GAG scaffolds. J Biomed Mater Res A. 89 363-369.

32. Choi JS, Yang HJ, Kim BS, Kim JD, Lee SH, Lee EK, Park K, Cho YW, Lee HY. 2010 Fabrication of porous extracellular matrix scaffolds from human adipose tissue. Tissue Eng Part C Methods. 16 387-396.

33. Guan J, Stankus JJ, Wagner WR. 2006 Development of composite porous scaffolds based on collagen and biodegradable poly(ester urethane)urea. Cell Transplant. 15 Suppl 1 S17-27.

34. Kempf M, Miyamura Y, Liu PY, Chen AC, Nakamura H, Shimizu H, Tabata Y, Kimble RM, McMillan JR. 2011 A denatured collagen microfiber scaffold seeded with human 
fibroblasts and keratinocytes for skin grafting. Biomaterials. 32 4782-4792. 


\section{Tables}

Table 1 Manufacturing conditions for the denatured collagen fiber scaffold

\begin{tabular}{lll}
\hline $\mathbf{p H}$ & P-temp $\left({ }^{\circ} \mathbf{C}\right)^{\mathbf{a}}$ & ${\text { P-time }(\mathrm{hr})^{\mathrm{b}}}^{\mathrm{a}}$ \\
\hline 7.4 & 50 & 6 \\
7.4 & 100 & 6 \\
7.4 & 100 & 24 \\
7.4 & 110 & 6 \\
7.4 & 120 & 6 \\
7.4 & 120 & 12 \\
7.4 & 120 & 18 \\
7.4 & 120 & 24 \\
7.4 & 130 & 6 \\
7.4 & 140 & 0 (no denaturation) \\
7.4 & 140 & 6 \\
7.4 & 140 & 9 \\
7.4 & 140 & 12 \\
7.4 & 140 & 24 \\
7.4 & 170 & 5 \\
7.4 & 170 & 6 \\
\hline
\end{tabular}

${ }^{\text {a }}$ P-temp, Processing temperature

${ }^{\mathrm{b}} \mathrm{P}$-time, Processing time 
Table 2 Relationship between manufacturing conditions and the properties of the denatured collagen fiber scaffold

\begin{tabular}{lllllll}
\hline pH & P-temp $\left({ }^{\circ} \mathrm{C}\right)^{\mathrm{a}}$ & P-time $(\mathrm{hr})^{\mathrm{b}}$ & Thickness $(\mu \mathrm{m})$ & Av $(\mu \mathrm{m})^{\mathrm{c}}$ & TS $^{\mathrm{d}}$ & BS $^{\mathrm{e}}$
\end{tabular}

\begin{tabular}{ccccccc}
\hline 7.4 & 50 & 6 & $0,0,0$ & 0 & 1 & IE (3) \\
7.4 & 100 & 6 & $0,0,0$ & 0 & 1 & IE (3) \\
7.4 & 100 & 24 & $0,0,0$ & 0 & 1 & IE (3) \\
7.4 & 110 & 6 & $0,0,0$ & 0 & 1 & IE (3) \\
7.4 & 120 & 6 & $0,0,0$ & 0 & 1 & IE (3) \\
7.4 & 120 & 12 & $0,0,0$ & 0 & 1 & IE (3) \\
7.4 & 120 & 18 & $0,0,0$ & 0 & 1 & IE (3) \\
7.4 & 120 & 24 & $275,334,833$ & 481 & 2.48 & 1 \\
7.4 & 130 & 6 & $0,0,0$ & 0 & 1 & IE (3) \\
7.4 & 140 & 0 & $0,0,0$ & 0 & 1 & IE (4) \\
7.4 & 140 & 6 & $701,827,1340$ & 956 & 2.96 & 3 \\
7.4 & 140 & 9 & $1263,1571,1692$ & 1509 & 3.51 & 2 \\
7.4 & 140 & 12 & $1215,1286,1930$ & 1477 & 3.48 & 1 \\
7.4 & 140 & 24 & $1810,2025,2286$ & 2040 & 4.04 & 1 \\
7.4 & 170 & 5 & $1619,1691,2000$ & 1770 & 3.77 & 1 \\
7.4 & 170 & 6 & $1691,2000,2029$ & 1907 & 3.91 & 1 \\
\hline
\end{tabular}

${ }^{\mathrm{a}} \mathrm{P}$-temp, Processing temperature

${ }^{\mathrm{b}}$ P-time, Processing time

${ }^{c}$ Av, Average thickness of 3 samples

${ }^{\mathrm{d}}$ TS, Thickness score

${ }^{\mathrm{e}} \mathrm{BS}$, Biocompatibility score

${ }^{\mathrm{f}}$ IE, Impossible to evaluate 


\section{Figures and figure Legends}
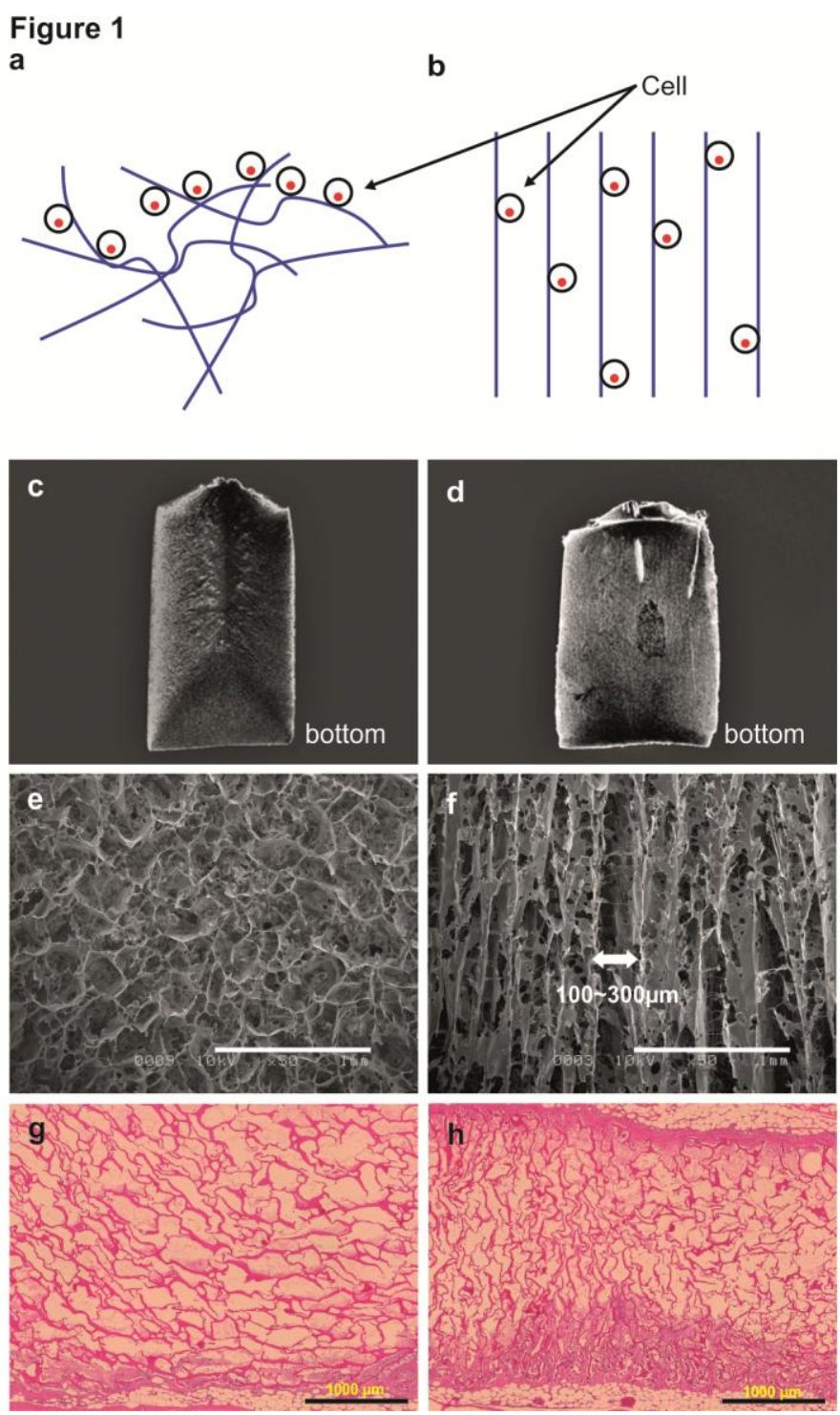

Figure 1 Difference between scaffolds with and without collagen fiber orientation

(a) Schematic illustration of the collagen fiber without orientation

(b) Schematic illustration of the collagen fiber with orientation (Cases a and b demonstrated cell infiltration into the scaffold, parallel to the collagen fiber)

(c) Macroscopic image of a vertical section of the collagen fiber scaffold without orientation 
(d) Macroscopic image of a vertical section of the collagen fiber scaffold with orientation (The contrast between figures (c) and (d) is coordinated to show the direction of collagen fiber in the scaffold).

(e) Electron-microscopic image of the collagen fiber scaffold without orientation

(f) Electron-microscopic image of the collagen fiber scaffold with orientation

(g) Scaffold without orientation of the collagen fiber (H-E image, 1 week after the operation)

(h) Scaffold with orientation of the collagen fiber

(H-E image, 1 week after the operation)

Scale bars represent $1000 \mu \mathrm{m}$ in $\mathbf{e}, \mathbf{f}, \mathbf{g}, \mathbf{h}$.

Figure 2
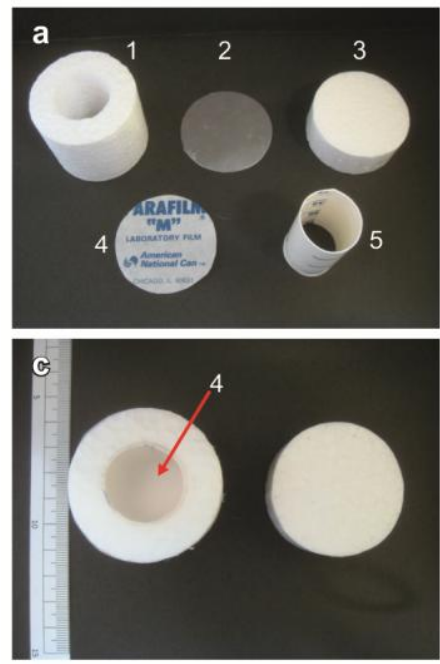

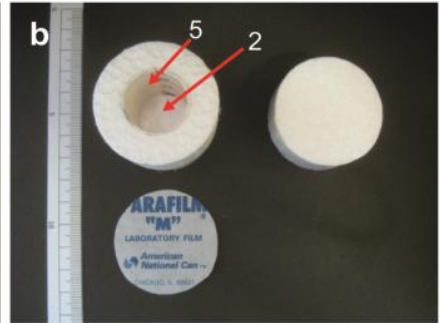

d

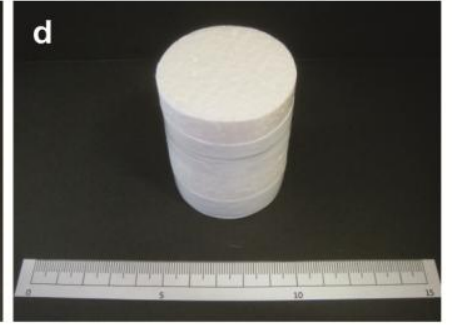

Figure 2 Containers that provide collagen fiber orientation

(a) 1. The outer frame is made of styrene foam; 2. Aluminum board; 3 . Lid made of styrene foam; 4. Parafilm; 5. The inner frame is a measuring cup made of paper.

(b) An aluminum board is attached to the bottom of the outer frame with vinyl tape, and the 
inner frame is installed.

(c) The volume of the collagen fiber suspension expands as it freezes and may touch a lid made of styrene foam. Parafilm is used to prevent mixing of the styrene foam with the collagen.

(d) The suspension is covered with a lid made of styrene foam and fixed with vinyl tape.

Cooling is applied from the lower side of the container, thus providing orientation to the collagen fiber scaffold.
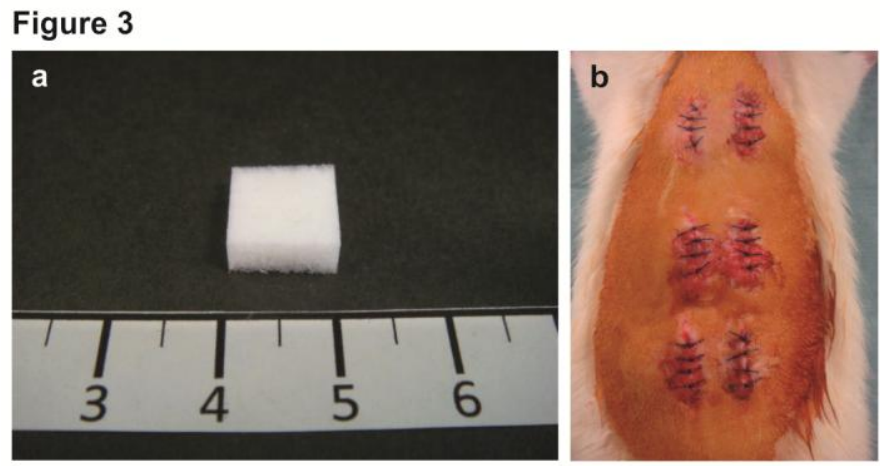

Figure 3 Collagen fiber scaffold and appearance just after it is embedded under the skin

(a) Collagen fiber scaffold $1 \mathrm{~cm} \times 1 \mathrm{~cm} \times 5 \mathrm{~mm}$

(b) Appearance just after embedding the collagen fiber scaffold under the back skin of a rat

\section{Figure 4}
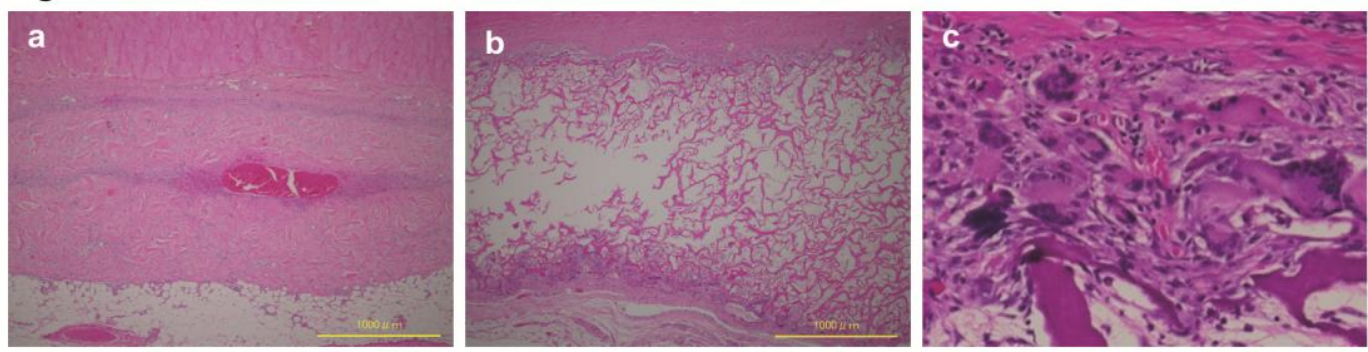

Figure 4 Collagen fiber scaffold with and without thermal denaturation at $140^{\circ} \mathrm{C}$ for $24 \mathrm{hr}$ 
(a) Collagen fiber scaffold without thermal denaturation after 1 week

(b) Collagen fiber scaffold with thermal denaturation $\left(140^{\circ} \mathrm{C}-24 \mathrm{hr}\right)$ after 2 weeks

(c) The foreign body giant cell identified around the scaffold (Fig. 4b)

Scale bars represent $1000 \mu \mathrm{m}$ in $\mathbf{a}, \mathbf{b}$ and $50 \mu \mathrm{m}$ in c. (H-E image) 
Figure 5

a

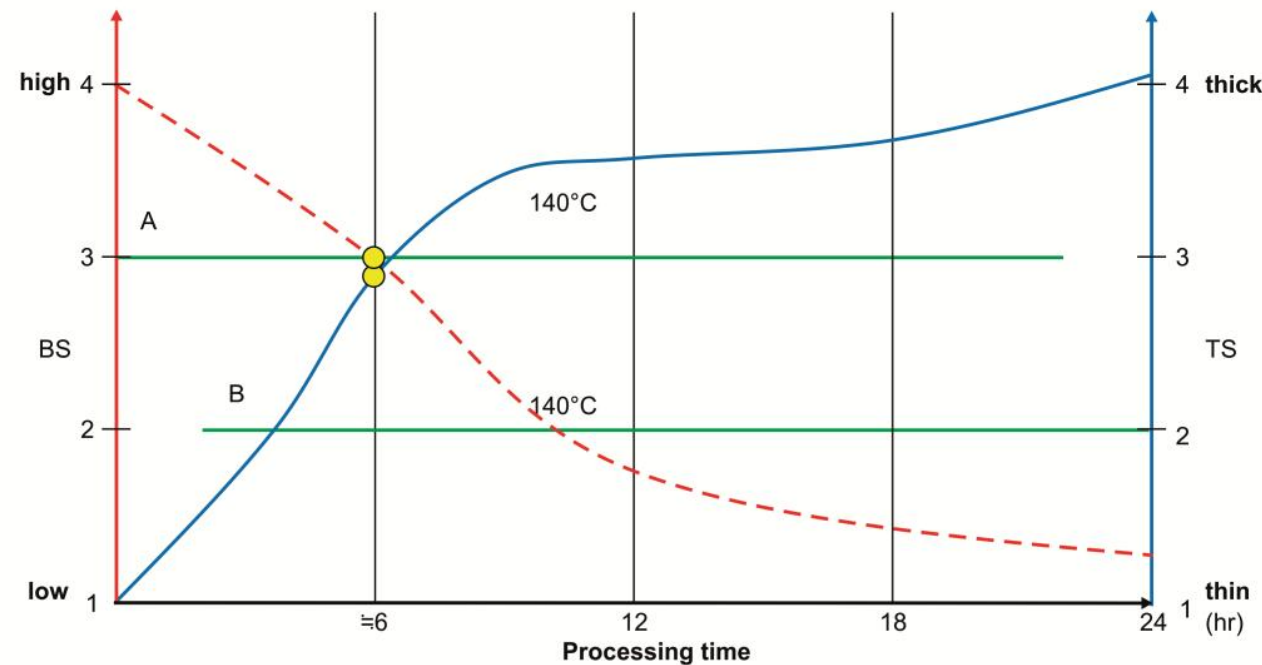

b
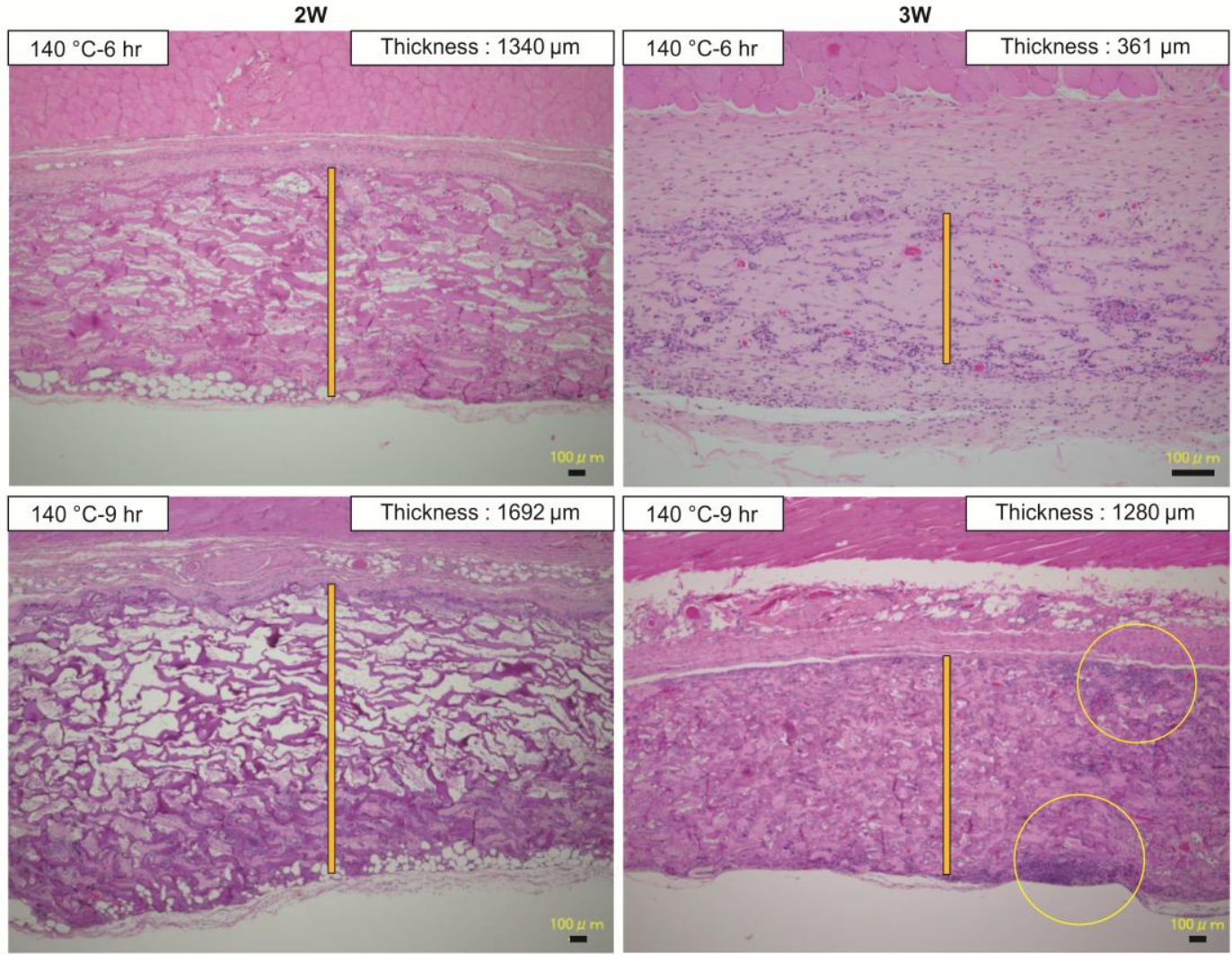

Figure 5 Relationship between thermal denaturation processing time and the space

maintenance ability and biocompatibility of a collagen fiber scaffold

(a) The red dashed line represents biocompatibility, and the blue line represents space 
maintenance ability. Line A represents the lowest level of biocompatibility (BS-3) and line

B represents the lowest level of space maintenance ability (TS-2) required for the scaffold.

(b) Thermal denaturation conditions are indicated on the left of each Figure and scaffold

thickness is indicated on the right. The yellow vertical line in each figure indicates the thickness of each scaffold. The part yellow circle indicates sites of inflammatory cell

infiltration. Scale bars represent $100 \mu \mathrm{m}$. (H-E image)

Figure 6
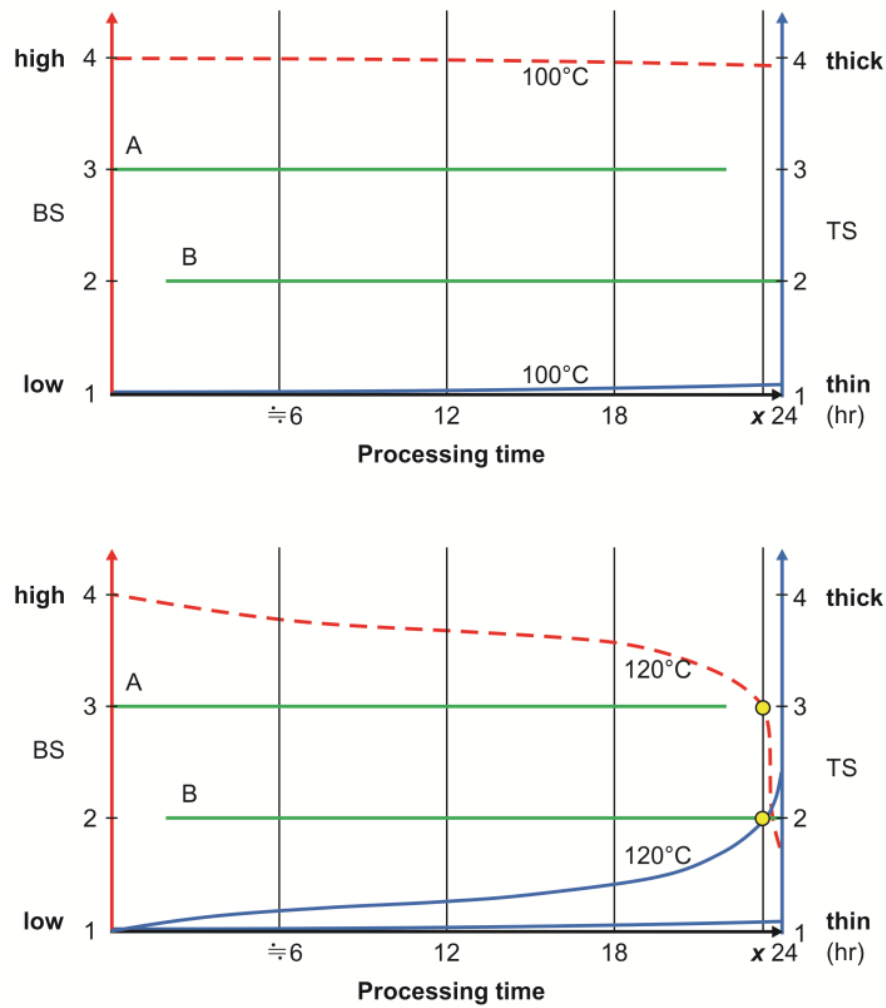

Figure 6 Relationship between thermal denaturation times and the space maintenance

\section{ability and biocompatibility of the collagen fiber scaffold}

The red dashed line represents biocompatibility, and the blue line represents space maintenance ability. Line A represents the lowest level of biocompatibility (BS-3) and line B represents the 
lowest level of space maintenance ability (TS-2) required for the scaffold. Time $\mathrm{x}$ indicates processing time when the denaturation temperature was $120^{\circ} \mathrm{C}$, suggesting the scaffold is similar to that made at $140^{\circ} \mathrm{C}-6 \mathrm{hr}$. 